Cahiers Charlevoix

Études franco-ontariennes
Cahiers Charlevoix Études franco-ontariennes

er Cresceosing"

\title{
Trois historiens de la " transition ". Mutations identitaires et historiographie en Acadie, en Ontario français et au Manitoba français, 1970-2000
}

\section{Yves Frenette}

Volume 12, 2018

URI : https://id.erudit.org/iderudit/1048916ar

DOI : https://doi.org/10.7202/1048916ar

Aller au sommaire du numéro

Éditeur(s)

Société Charlevoix

Presses de l’Université d’Ottawa

ISSN

1203-4371 (imprimé)

2371-6878 (numérique)

Découvrir la revue

Citer cet article

Frenette, Y. (2018). Trois historiens de la « transition ». Mutations identitaires et historiographie en Acadie, en Ontario français et au Manitoba français, 1970-2000. Cahiers Charlevoix, 12, 55-88. https://doi.org/10.7202/1048916ar
Résumé de l'article

Yves Frenette, qui en est à sa cinquième participation aux Cahiers Charlevoix, propose un regard comparatif de l'historiographie dans trois aires de la francophonie canadienne entre 1970 et 2000. Au cours de cette période de transition, les identités traditionnelles acadienne et canadienne-française déclinent progressivement au profit de nouvelles identités francophones provincialisées. Il s'attache à trois historiens qui sont aussi des intellectuels enracinés dans leur milieu : Léon Thériault au Nouveau-Brunswick, Gaétan Gervais en Ontario et Robert Painchaud au Manitoba. Les deux premiers se rejoignent dans leur quête d'autonomie pour les Acadiens et les Franco-Ontariens - autonomie politique pour Thériault, autonomie institutionnelle pour Gervais ; ils font ressortir des filiations qui, seules, garantissent un avenir établi sur des assises solides. Dans un contexte fort différent, surtout en raison de la situation très minoritaire des francophones de la Prairie, Painchaud étudie la thématique historique de l'immigration, prône l'ouverture à l'autre et appuie les nouvelles politiques fédérales et provinciales de multiculturalisme. 


\title{
Trois historiens de la «transition ». Mutations identitaires et historiographie en Acadie, en Ontario français et au Manitoba français, 1970-2000
}

\author{
Yves FrenetTE
}

Chaire de recherche du Canada sur les migrations, les transferts et les communautés francophones Université de Saint-Boniface 


\section{SOMMAIRE}

$\begin{array}{ll}\text { INTRODUCTION } & 57\end{array}$

$\begin{array}{ll}\text { I - LE CONTEXTE } & 58\end{array}$

II - Les Historiens, MAîtres D'EUVRE D'UNE NOUVELLE DYNAMIQUE IDENTITAIRE 63

A. Léon Thériault et l'autonomisation politique des Acadiens 64

B. Gaétan Gervais ou l'ancrage historique des Franco-Ontariens 69

C. Robert Painchaud : 1'ambiguïté identitaire des Franco-Manitobains $\quad 77$

$\begin{array}{ll}\text { CONCLUSION } & 85\end{array}$ 


\section{Trois historiens de la « transition ». Mutations identitaires et historiographie en Acadie, en Ontario français et au Manitoba français, 1970-2000 ${ }^{1}$}

\section{INTRODUCTION}

Notre texte porte sur l'historiographie dans trois aires de la francophonie canadienne entre 1970 et 2000 . Notre objectif consiste plus particulièrement à étudier la contribution de trois historiens à l'élaboration d'une mémoire collective en contexte de mutations identitaires. Il s'agit de Léon Thériault au Nouveau-Brunswick, de Gaétan Gervais en Ontario et de Robert Painchaud au Manitoba.

1. Ce texte a eu une longue gestation. Ses premiers balbutiements remontent à une table ronde intitulée «Échanges historiographiques entre le Québec et la francophonie », au congrès annuel de l'Institut d'histoire de l'Amérique française, à Hull, en octobre 2001. Puis nous en présentâmes une première version sous le titre « L'Historiographie en devenir des francophones de l'Ontario et de l'Ouest canadien » au colloque « De Québec à l'Amérique. L'Amérique française entre histoire et mémoire », Commission franco-québécoise sur les lieux de mémoire communs, Musée de la civilisation, Québec, septembre 2003. Légèrement modifié, le texte fut ensuite communiqué, sous le titre "Transformations identitaires et historiographie. L'Acadie, l'Ontario français et l'Ouest francophone, 1970-2000 ", aux participants du colloque "Lieux de mémoire, commémoration et identité dans la francophonie canadienne », Université d'Ottawa, novembre 2006. Deux ans plus tard, soit en mai 2008, il nous servit de base pour discuter de nouveau des «Échanges historiographiques entre le Québec et les communautés francophones. Mutations et permanences », à l'occasion du colloque "Vues d'ici et d'ailleurs », organisé dans le cadre du colloque du Réseau de la recherche sur la francophonie canadienne, au congrès annuel de l'Association francophone pour le savoir. Un peu plus tard, nous formulions avec François-Olivier Dorais, alors candidat à la maîtrise à l'Université d'Ottawa, le projet de rédiger un article sur les historiens de la «transition ». Cet écrit ne vit pas le jour, mais nous avons grandement profité de la connaissance intime de l'œuvre de Gaétan Gervais qu'en a ce jeune historien. Qu'il trouve ici l'expression de nos remerciements sincères. Voir François-Olivier Dorais, « Gaétan Gervais. Témoin et agent d'une mutation référentielle en Ontario français », Mens. Revue d'histoire intellectuelle et culturelle, vol. 13, $\mathrm{n}^{\circ}$ 2, printemps 2013, p. 59-99; Id., « Gaétan Gervais. Un intellectuel franco-ontarien entre ruptures et constantes », dans Jean-François Laniel et Joseph-Yvon Thériault (dir.), Retour sur les États généraux du Canada français. Continuités et ruptures d'un projet national, Québec, Presses de l'Université du Québec, 2016, p. 109-142 ; Id., Un historien dans la Cité. Gaétan Gervais et l'Ontario français, Ottawa, Presses de l'Université d'Ottawa, 2016, 264 p. 
Ces trois intellectuels sont enracinés dans leur milieu et sont emblématiques du rôle joué par l'historiographie dans la recomposition identitaire de la francophonie canadienne à la fin du $\mathrm{Xx}^{\mathrm{e}}$ siècle. À quel contexte l'avènement de ces prises de parole historiennes répond-il? Quelles sont les similarités et les variantes que l'on peut dégager dans les travaux de Thériault, Gervais et Painchaud? Quels axes d'analyse privilégient-ils ?

Notre travail s'effectuera en trois étapes. Après avoir présenté brièvement le contexte identitaire et le cadre qui mobilisent notre questionnement, nous consacrerons la deuxième partie de notre texte à l'étude des œuvres scientifiques et militantes de ces trois historiens de la «transition ». Nous montrerons que ces chercheurs ont participé à un processus de construction mémorielle qui participait d'une même ambition, soit celle de redéfinir la référence identitaire des groupes auxquels ils appartenaient sur des assises historiques faites d'ancien et de nouveau. En conclusion, nous comparerons les parcours de Thériault, de Gervais et de Painchaud en tentant de faire la part des facteurs constitutifs à l'élaboration de leurs travaux.

\section{I - LE CONTEXTE}

Les mutations identitaires dont il est question ici sont l'aboutissement d'une longue évolution, sous l'action concertée d'une multiplicité de facteurs. D'un point de vue macrosociologique, nous pourrions rendre compte de ces transformations à la lumière du concept de référence développé par Fernand Dumont, tout comme l'a proposé Michel Bock ${ }^{2}$. Selon l'interprétation dumontienne, le tournant des années 1960 marque, pour les communautés francophones minoritaires, la sortie définitive de la « référence canadienne-française » et la transition vers une référence remaniée regroupant les francophones de chaque province en com-

2. Michel Bock, « De la solidarité canadienne-française à l'éclatement des références. La mutation des identités québécoise et franco-ontarienne », dans JeanFrançois Savard, Alexandre Brassard et Louis Côté (dir.), Les Relations Québec Ontario. Un destin partagé ? Québec, Presses de l'Université du Québec, 2011, p. 83-105. 
munautés particulières, distinctes du Québec ${ }^{3}$. Pour comprendre ce processus de recomposition identitaire, il faut se reporter aux transformations sociopolitiques et intellectuelles des décennies d'après-guerre. S'élabore alors au Québec un projet politique orienté vers une plus grande autonomie provinciale. La modernisation de l'État québécois, devenu le lieu de l'émancipation économique, politique et culturelle des Canadiens français, oblige à ce moment le nationalisme canadien-français, appuyé par une élite traditionnelle, très près de l'institution ecclésiale, à repenser la logique de son encadrement social ${ }^{4}$. L'État du Québec crée alors de nouvelles structures et prend en charge presque toutes les sphères gérées par l'Église, en perte rapide de ses effectifs cléricaux. En parallèle, s'accélère l'urbanisation des Canadiens qui, propulsée par la croissance du secteur tertiaire, bouleverse les mœurs et les pratiques culturelles ${ }^{5}$. À l'extérieur du Québec, le réseau institutionnel se démantèle lentement, pour être repris en grande partie, lui aussi, par les gouvernements provinciaux et l'État fédéral ${ }^{6}$.

Ces lentes et profondes transformations obligent les Canadiens français à se redéfinir tant dans l'espace que dans leur rapport à eux-mêmes. L'émergence de l'État providence canadien et l'affirmation progressive du néonationalisme québécois président

3. Fernand Dumont, Genèse de la société québécoise, Montréal, Boréal, 1993, 400 p. ; Id., «Essor et déclin du Canada français », Recherches sociographiques, vol. 38, n³, 1997, p. 419-467. Voir aussi Danielle Juteau, «Ontarois et Québécois. Relations hors frontières ? ", dans Dean Louder et Eric Waddell (dir.), Du continent perdu à l'archipel retrouvé. Le Québec et l'Amérique française, Québec, Presses de l'Université Laval, 1983, p. 41-53.

4. Joseph-Yvon Thériault, « Entre la nation et l'ethnie. Sociologie, société et communautés minoritaires francophones ", Sociologie et sociétés, vol. 26, n 1, printemps 1994, p. 24.

5. Kenneth McRoberts et Dale Postgate, Développement et modernisation du Québec, Montréal, Boréal, 1983, 352 p. Voir aussi les analyses pionnières d'Hubert Guindon, Tradition, modernité et aspiration nationale de la société québécoise, Montréal, Éditions Saint-Martin, 1990, 233 p.

6. Marcel Martel, Le Deuil d'un pays imaginé. Rêves, lutte et déroute du Canada français : les rapports entre le Québec et la francophonie canadienne (18671975), Ottawa, Centre de recherche en civilisation canadienne-française et Presses de l'Université d'Ottawa, 1997, p. 107-187 ; Yves Frenette, Brève Histoire des Canadiens français, Montréal, Boréal, 1998, p. 169-194. 
à un important processus de réaménagement identitaire qui concourt au déclin de la référence nationale canadienne-française sur plusieurs décennies ${ }^{7}$. En effet, ce néonationalisme, dont les premiers théoriciens gravitent autour de l'École historique de Montréal, critique de façon parfois virulente les fondements du traditionalisme. Une nouvelle génération d'intellectuels, regroupés au sein de revues comme Cité Libre ou Parti Pris, de même que certains membres du clergé ne manquent pas non plus de fustiger cette idéologie ${ }^{8}$. La nation canadienne-française telle qu'elle a été pensée par l'élite traditionaliste, c'est-à-dire non pas comme une entité étatique mais comme une communauté d'histoire, de langue, de foi et de culture, disparaît progressivement. Sur le plan politique, elle en vient à ne plus correspondre aux critères citoyens de la nation québécoise, désormais définie en fonction du cadre étatique provincial. Ce point de discordance éclate au grand jour au moment des États généraux du Canada français de 1969, qui affaiblissent le Canada français comme structure et comme pôle de référence identitaire ${ }^{9}$. Cependant, tout du moins en Ontario, la référence canadienne-française subsiste au moins jusqu'au début des années quatre-vingt ${ }^{10}$.

Le changement de paradigme identitaire découle donc en partie des transformations structurelles du Canada français

7. Pour une étude pancanadienne des années de transition du point de vue linguistique, voir Marcel Martel et Martin Pâquet, Langue et politique au Canada et au Québec. Une synthèse historique, Montréal, Boréal, 2010, p. 129-272.

8. Michael Behiels, Prelude to Quebec's Quiet Revolution. Liberalism vs NeoNationalism, 1945-60, Montréal et Kingston, McGill-Queen's University Press, 1985, 384 p. ; E.-Martin Meunier et Jean-Philippe Warren, Sortir de la " Grande Noirceur». L’horizon "personnaliste » de la Révolution tranquille, Québec, Septentrion, 2002, 214 p. ; Michael Gauvreau, Les Origines catholiques de la Révolution tranquille, Montréal, Fides, 2008, 457 p.

9. Laniel et Thériault, op. cit., 411 p. ; Marcel Martel (dir.), Les États généraux $d u$ Canada français. Trente ans après, Ottawa, Centre de recherche en civilisation canadienne-française, 1997, $422 \mathrm{p}$.

10. Serge Dupuis, « On prévoyait le déluge ! La résistance franco-ontarienne au rapatriement de la Constitution canadienne : 1977-1982 », Revue du Nouvel-Ontario, no 33, 2008, p. 7-39 ; Serge Miville, « "À quoi sert au Canadien-Français de gagner l'univers canadien s'il perd son âme de francophone ?" Représentations identitaires et mémorielles dans la presse franco-ontarienne après la "rupture" du Canada français (1969-1986) », thèse de maîtrise (histoire), Université d'Ottawa, 2012, 246 p. 
d'après-guerre associées à l'émergence de l'État providence et des phénomènes conjugués de sécularisation et de laïcisation. Avec la mise en place de réseaux scolaires provinciaux, la laïcisation des institutions postsecondaires, la multiplication des associations provinciales et le développement des productions culturelles, les décennies suivantes seront vécues sur le mode de l'institutionnalisation de cadres identitaires provinciaux. De leur côté, les Québécois s'engagent dans une démarche d'affirmation politique sise à l'intérieur de leurs frontières et dans l'indifférence généralisée du sort des minorités francophones. À l'intérieur de celles-ci, la transformation est parfois vécue et interprétée comme une rupture, une rupture qui suscite beaucoup d'amertume ${ }^{11}$.

L'Acadie connaît aussi de grands bouleversements. Comme au Canada français, une nouvelle élite participe à l'avènement de la modernité en transformant les institutions de la Survivance, que ce soit dans le domaine religieux, coopératif, hospitalier, communautaire ou scolaire, et la sphère organisationnelle se voit en grande partie prise en charge par l'État. En outre, l'Acadie se segmente en composantes provinciales. C'est ainsi que naissent dans les années soixante-dix la Société des Acadiens du NouveauBrunswick, la Fédération des Acadiens de la Nouvelle-Écosse et la Fédération des francophones de Terre-Neuve et du Labrador, pendant que la vénérable Société Saint-Thomas d'Aquin de l'Île-du-Prince-Édouard précise son statut provincial. Cette provincialisation institutionnelle vient confirmer le contraste entre l'Acadie néo-brunswickoise et les Acadiens des trois autres provinces atlantiques. C'est la première qui affirme avec le plus de force son identité et qui résiste bien à l'assimilation linguistique. Ailleurs, les transferts linguistiques vers l'anglais adoptent un rythme dramatique à partir des années soixante-dix ${ }^{12}$.

Au Nouveau-Brunswick, l'affirmation des Acadiens est, entre autres, politique, particulièrement à partir de l'accession

11. Joseph-Yvon Thériault, «Les États généraux et la fin du Canada français », dans Marcel Martel, Les États généraux du Canada français, op. cit., p. 265-267.

12. Recensement du Canada (imprimé), 1971-2001. 
au pouvoir, le 27 juin 1960, d'un jeune avocat libéral de 34 ans, Louis J. Robichaud, dont le programme contient plusieurs réformes importantes et repose sur la notion de « chance égale pour tous ». Robichaud est le premier Acadien à être élu premier ministre du Nouveau-Brunswick. Ardent promoteur de justice sociale, il ordonne en 1964 la création d'une Commission royale d'enquête sur l'enseignement supérieur, la Commission Deutsch, qui recommande la création de l'Université de Moncton. En 1969, un an avant sa défaite, le gouvernement Robichaud fait adopter la Loi sur les langues officielles, le Nouveau-Brunswick devenant ainsi la seule province officiellement bilingue au Canada ${ }^{13}$. En pratique, cela veut dire que les Acadiens ont le droit d'obtenir des services dans leur langue maternelle devant les tribunaux et dans l'administration publique provinciale. En 1981, le gouvernement conservateur de Richard Hatfield ira plus loin, en adoptant une loi qui reconnaît l'égalité des deux communautés linguistiques.

Pour de nombreux jeunes, mais aussi des moins jeunes, les stratégies de l'élite traditionnelle, qui applaudit les réformes du gouvernement Robichaud, sont trop timides. Ils accusent les membres de l'élite d'enfermer les Acadiens dans un carcan idéologique étroit, certains considérant même qu'elle est carrément dictatoriale. En outre, sous des dehors revendicateurs, elle serait inféodée à la majorité anglophone. Enfin, elle utiliserait le nationalisme acadien pour servir ses intérêts de classe. Certains militants favorisent plutôt une approche radicale face à la majorité de langue anglaise, n'acceptant plus d'être humiliés. Dans ce contexte, des problèmes financiers à l'Université de Moncton en 1968 occasionnent une série de manifestations dans les rues de la ville lors desquelles les étudiants exigent l'égalité entre les deux groupes linguistiques. Ils revendiquent ni plus ni moins un relèvement économique et culturel pour pallier le sous-développement de l'Acadie. Ils réclament, entre autres, des écoles de langue française là où elles n'existent pas et des services

13. Michel Cormier, Louis J. Robichaud. Une révolution si peu tranquille, Lévis, Éditions de la Francophonie, 2004, 302 p. 
égaux à ceux des anglophones, notamment dans le domaine de l'éducation ${ }^{14}$.

En 1972, l'affirmation politique des Acadiens devient électorale avec la fondation du Parti acadien par des intellectuels du nord-est du Nouveau-Brunswick qui s'inspirent du Parti québécois. Se voulant le porte-parole de la communauté et une alternative aux partis conservateur et libéral, la nouvelle formation entend éduquer et politiser la population. Ses chefs savent qu'ils n'accéderont pas au pouvoir, mais ils entendent jouer un rôle de représentation et d'influence. Pour que l'Acadie s'épanouisse, le parti élabore un programme réformiste fondé sur une intervention massive de l'État. Toutefois, il est tiraillé entre une aile socialiste et une aile nationaliste. La victoire de cette dernière est confirmée lorsque l'idée de la création d'une province acadienne entre dans le programme officiel du parti en 1977. La formation disparaît cinq ans plus tard sans avoir fait élire de député à Frédéricton, mais son dynamisme et la vigueur de ses positions ont forcé les vieux partis à se tourner davantage vers l'électorat de langue française ${ }^{15}$.

\section{II - LeS HISTORIENS, MAÎTRES D'EUVRE D'UNE NOUVELLE DYNA- MIQUE IDENTITAIRE}

Le processus de fragmentation provinciale des identités francocanadiennes favorise l'élaboration de nouveaux discours sur la communauté d'appartenance et sur la recomposition de ses lieux d'affirmation ${ }^{16}$. Parmi les maîtres d'œuvre de ces nouveaux discours, les trois historiens à l'étude occupent une place de choix.

14. Joël Belliveau, Le " Moment 68 » et la réinvention de l'Acadie, Ottawa, Presses de l'Université d'Ottawa, 2014, 311 p.

15. Roger Ouellette, Le Parti acadien. De la fondation à la disparition, 19721982, Moncton, Chaire d'études acadiennes, 1992. 119 p. ; Michael Poplyanski, «"L'Acadie aux Acadiens". Le nationalisme du Parti acadien, 1977-1982 », Acadiensis, vol. XLII, $\mathrm{n}^{\circ} 2$ été-automne 2013, p. 75-91 ; Philippe Volpé et Julien Massicotte, " Choisir son utopie. Le Parti acadien et la gauche ", dans Michelle Landry, Martin Pâquet et Anne Gilbert (dir.), Mémoires et mobilisations, Québec, Presses de 1'Université Laval, 2015, p. 161-194.

16. Marie LeBel, «Le Discours comme patrie. Les intellectuels franco-ontariens comme interprétants de la condition historique et identitaire de l'Ontario français "), thèse de doctorat (histoire), Université Laval, 2009, p. 232 sqq. 
Par leurs réflexions et leurs actions, ils participent à un processus de construction mémorielle visant à enraciner de nouveaux paramètres identitaires dans un contexte où la référence au projet national acadien et canadien-français est remise en cause.

\section{A. Léon Thériault et l'autonomisation politique des Acadiens} Comme 1'a montré Julien Massicotte, cette période d'effervescence ne manquera pas d'influer sur la manière dont les historiens écrivent l'histoire. Une génération d'historiens va s'affirmer et en appellera à un renouvellement de l'historiographie acadienne ${ }^{17}$. Leur engagement dans les milieux du savoir historique sera mis au service d'un projet visant à redonner corps à une expérience collective porteuse de sens. Ces historiens ont «[...] affiché le souci [...] d'être au service de l'idéal politique censément nécessaire à l'épanouissement de leur communauté. Ils s'efforcent d'allier à la tâche de $l^{\prime}$ historien celle de l'intellectuel ${ }^{18}$ ». Léon Thériault en est peut-être l'exemple le plus probant.

Natif du Nouveau-Brunswick, Thériault fait ses études classiques au Collège de Bathurst et milite au sein de 1'Union générale des étudiants acadiens, fondée au début de 1964. Deux ans plus tard, lorsque les représentants étudiants de l'Université de Moncton favorisent une union des associations étudiantes du Nouveau-Brunswick sans égard à la langue, il s'y oppose avec vigueur ${ }^{19}$. Formé en histoire à l'Université Laval et à l'Université du Nouveau-Brunswick, il revient en Acadie en 1969 comme professeur à la jeune Université de Moncton, où il inaugure l'enseignement de l'histoire acadienne. En parallèle, il s'engage dans la Société historique acadienne, au sein de laquelle il occupe diverses fonctions, dont celle de président et de rédacteur en chef de ses cahiers, en plus d'y publier plusieurs articles ${ }^{20}$. Avec son

17. Julien Massicotte, «Les Nouveaux Historiens de l'Acadie », Acadiensis, vol, XXXIV, $\mathrm{n}^{\circ} 2$, printemps 2005, p. 147-155.

18. Ibid., p. 153.

19. Joël Belliveau, op. cit., p. 67-119.

20. Léon Thériault, «Les Examens dans les écoles du Nouveau-Brunswick. Lamèque 1880 », Les Cahiers de la Société historique acadienne, vol. 10, n 1, mars 
collègue Jean Daigle, il contribue à rapprocher historiens dits amateurs et professionnels de l'histoire. Thériault est très présent sur la scène médiatique, commentant les sujets d'actualité acadienne, et il participe à nombre de comités au sein de la Société de l'Acadie du Nouveau-Brunswick ${ }^{21}$.

Dès sa fondation, Thériault adhère au Parti acadien pour y faire valoir un projet de création d'une province acadienne. En 1973, il distribue aux militants de la formation politique réunis en congrès un texte intitulé «La Réalité politique des Acadiens » dans lequel il célèbre l'autonomie des Acadiens depuis le $\mathrm{XIX}^{\mathrm{e}}$ siècle. Pour lui, il y a une filiation directe entre les organisateurs de la première convention acadienne, en 1881, et les chefs du Parti acadien. En 1977, il joue un rôle important dans le virage nationaliste que prend le parti, en mettant au centre de sa plateforme la création d'une province acadienne. Candidat en lice aux élections provinciales de 1978, il est le seul ténor de la formation à prôner une ouverture aux anglophones et aux immigrants, ce qui correspond à sa conception civique de l'identité acadienne ${ }^{22}$.

Comme historien, Thériault formule en 1973 « une nouvelle orientation de l'histoire acadienne » en s'écriant «Arrêtons de faire l'histoire de l'Acadie et commençons celle des Acadiens ${ }^{23}$ ». Il signifie par là que les historiens doivent dépasser à la fois le providentialisme et l'événementiel pour proposer une interprétation globale de l'histoire acadienne. Il propose d'aborder des thèmes inédits, d'explorer de nouvelles approches, d'émettre des hypothèses originales. Il donne lui-même l'exemple en faisant paraître un article sur les relations entre missionnaires et

1979, p. 51-52 ; Id., « La Première Convention nationale », Les Cahiers de la Société historique acadienne, vol. 12, nº 1, 1981, p. 5-11.

21. Philippe Volpé, « Hommage à Léon Thériault », lauréat 2017 du Prix du CrCCF, Université d'Ottawa, au http://arts.uottawa.ca/crccf/sites/arts.uottawa. ca.crccf/files/hommage-a-leon-theriault-crccf-final.pdf.

22. Michael Poplyanski, op. cit., p. 82-88 ; Léon Thériault, La Question du pouvoir en Acadie, Moncton, Éditions d'Acadie, 1982, p. 60-61.

23. Léon Thériault, « Pour une nouvelle orientation de l'histoire acadienne », Revue de l'Université de Moncton, vol. 6, n² 2, 1973, p. 124. Reproduit dans Mourad Ali-Khodja et Annette Boudreau (dir.), Lectures de l'Acadie. Une anthologie de textes en sciences humaines et sociales, 1960-1994, Montréal, Fides, 2009, p. 205-216. 
paroissiens dans la période postérieure au Grand Dérangement et une synthèse d'histoire acadienne ${ }^{24}$. Pour Thériault, l'identité acadienne des années soixante et soixante-dix est née dans les premières décennies du régime confédératif, lorsque, ayant pris conscience de la distinction acadienne, l'élite a décidé de fournir au peuple des outils (journaux, collèges classiques, symboles nationaux), puis des projets collectifs. Cette prise de conscience s'est faite de façon autonome et doit peu à la France et au Québec. Il choisit d'ailleurs pour titre d'un de ses textes « L'Acadianisation de l'Église catholique en Acadie ${ }^{25} »$. Vingt ans plus tard, il modifiera quelque peu son discours en écrivant que les Acadiens du Nouveau-Brunswick ont beaucoup reçu du Québec ${ }^{26}$.

En 1982, Thériault publie un essai percutant intitulé La Question du pouvoir en Acadie. S'appuyant sur sa lecture de l'histoire acadienne et n'ayant plus besoin, en raison du genre choisi, d'y mettre les nuances et l'appareil scientifique de l'historien, Thériault prône l'acadianisation du politique, secteur fondamental qui échappe encore aux Acadiens du Nouveau-Brunswick. Selon lui, ces derniers doivent se doter d'un « projet politique spécifiquement acadien », c'est-à-dire la création d'une province acadienne, point d'arrivée d'un long cheminement historique :

$[\ldots]$ je ne vois pas dans ma démarche quelque chose de tout à

24. Léon Thériault, «Les Missionnaires et leurs paroissiens dans le nord-est du Nouveau-Brunswick, 1766-1830", Revue de l'Université de Moncton, vol. 9, $\mathrm{n}^{\text {os }}$ 1-3, octobre 1976, p. 31-51; Id., " L'Acadie, 1763-1978. Synthèse historique », dans Jean Daigle (dir.), Les Acadiens des Maritimes, Études thématiques, Moncton, Centre d'études acadiennes, 1980, p. 49-93 ; Id., «L'Acadie de 1763 à 1990. Synthèse historique ", dans Jean Daigle (dir.), L'Acadie des Maritimes. Études thématiques des débuts à nos jours, Moncton, Chaire d'études acadiennes, 1993, p. 45-91. Thériault rédige aussi un Petit Manuel d'histoire d'Acadie, de 1755 à 1867, Moncton, Librairie acadienne, Université de Moncton, 1976. Nous n'avons pu le consulter.

25. Léon Thériault, «L'Acadianisation de l'Église catholique en Acadie », dans Daigle, Les Acadiens des Maritimes, op.cit., p. 293-371. Pour la deuxième édition de l'ouvrage dirigé par Daigle, l'auteur modifie le titre : " L'Acadianisation des structures ecclésiastiques aux Maritimes ", dans Daigle, L'Acadie des Maritimes, op.cit., p. 431-466.

26. Id., « L’Acadie du Nouveau-Brunswick et le Québec. Froideur ou méfiance (1880-1960) ? », dans Fernand Harvey et Gérard Beaulieu (dir.), Les Relations entre le Québec et l'Acadie, 1880-2000. De la tradition à la modernité, Québec et Moncton, Éditions de l'IQRC et Éditions d'Acadie, 2000, p. 70-71. 
fait étranger au cheminement de notre peuple et je dois ici ma profonde reconnaissance à toute une lignée de patriotes qui, depuis plus de cent ans, depuis même l'époque du Régime français, n'ont vraiment jamais renoncé à rétablir l'Acadie dans ses droits et à démarquer son territoire. Colons du $17^{\mathrm{e}}$ siècle, déportés de 1755 , nationalistes de 1881, Acadiens de 1982, que d'assauts n'avons-nous pas subis ! Mais, aussi, que d'entêtement dans notre volonté de nous maintenir ! ${ }^{27}$

Thériault répond alors au militant syndical et intellectuel Michel Roy qui a publié en 1978 une attaque virulente contre le clergé et l'élite laïque acadienne ${ }^{28}$. Mais surtout, sans jamais y faire référence, il reprend les thèses des historiens de l'École de Montréal ${ }^{29}$. L'Acadie française de Thériault était une terre de petits fermiers qui avaient appris à apprivoiser leur environnement maritime. Sur ce territoire, ils formaient une majorité dotée d'une sorte de projet collectif qui, malheureusement, contrecarrait les intérêts des colonies anglo-américaines. L'Acadie fut donc conquise par l'Angleterre en 1710, une défaite confirmée par le Traité d'Utrecht trois ans plus tard. Pendant un temps, les Acadiens réussirent à maintenir une neutralité précaire, mais la raison du plus fort prévalut et ils furent déportés. Quand ils se réinstallèrent dans les Provinces maritimes au cours des années et des décennies suivantes, ils étaient devenus minoritaires :

[...] le projet acadien se trouvait en quelque sorte brisé après 1713, détourné de ses orientations originelles. L'Acadie serait désormais coupée de ses liens naturels si essentiels avec la France et le monde francophone, à une époque justement où elle en avait encore tant besoin. Il n'y aurait plus d'immigration française en Nouvelle-Écosse. Un projet anglophone se substituait, par la force des armes, au projet acadien. La question $d u$ pouvoir dès lors était déjà posée. ${ }^{30}$

27. Léon Thériault, La Question du pouvoir en Acadie, op. cit., p. 13.

28. Michel Roy, L'Acadie perdue, Montréal, Québec-Amérique, 1978, 204 p.

29. Sur les historiens de l'École de Montréal, voir Jean Lamarre, Le Devenir du Québec, selon Maurice Séguin, Guy Frégault et Michel Brunet (1944-1969), Québec, Septentrion, 1993, $561 \mathrm{p}$.

30. Léon Thériault, La Question du pouvoir en Acadie, op. cit., p. 86. 
Exclus du pouvoir, les Acadiens formèrent alors une société parallèle à celle des « usurpateurs ». Entre les deux groupes, s'établit une contradiction profonde que rien ne pouvait faire disparaître. Ce n'est qu'à partir du milieu du XIX ${ }^{\mathrm{e}}$ siècle que l'élite créa des instruments « d'envergure collective ». Reconnaissant que cette élite défendait des intérêts de classe, Thériault refuse de voir en elle, comme Michel Roy et Régis Brun, des exploiteurs du peuple acadien $^{31}$. Toutefois, il reproche aux créateurs de la Renaissance acadienne de s'être arrêtés en route et de n'avoir pu ou de n'avoir pas voulu investir le champ du politique. Sur cette base, Thériault propose un programme détaillé d'acadianisation du politique, dont l'aboutissement logique est l'autodétermination. Pour y parvenir, les Acadiens du Nouveau-Brunswick doivent s'unir et bâtir sur les acquis du passé :

Vouloir rompre totalement avec nos institutions acadiennes actuelles ou nos expériences collectives du passé ne ferait que hâter l'échec face aux objectifs que nous cherchons à atteindre. Le peuple acadien ne se retrouverait pas dans une démarche qui ferait table rase de tout ce que nous avons construit jusqu'ici. J'estime en fait qu'il faut être novateur et réformiste tout en ignorant d'inutiles brisures avec notre héritage acadien [...]. Nos devanciers ont toujours perçu les Acadiens comme une entité cohérente; ils ont insisté sur la solidarité, sur l'union des forces. Leur message tient encore aujourd'hui. ${ }^{32}$

Thériault a ainsi une conception prospective de l'histoire, qui est « orientée vers un projet d'avenir dans lequel s'inscrirait l'Acadie, un projet foncièrement politique ${ }^{33} »$.

La désillusion conséquente à la disparition du Parti acadien en 1982 explique sans doute, du moins en partie, le retrait de Léon Thériault à la fois comme historien et comme intellectuel public. En effet, à partir de ce moment, ses interventions se feront plus

31. Michel Roy, op. cit. ; Régis Brun, De Grand-Pré à Kouchibougouac. L'histoire d'un peuple exploité, Moncton, Éditions d'Acadie, 1982, $175 \mathrm{p}$.

32. Léon Thériault, La Question du pouvoir en Acadie, op. cit., p. 218.

33. Julien Massicotte, « Du sens de l'histoire. Les historiens acadiens et leur représentation de l'histoire, 1950-2000», dans Patrick D. Clarke (dir.), Clio en Acadie. Réflexions historiques, Québec, Presses de l’Université Laval, 2014, p. 84. 
rares, tout comme ses publications ${ }^{34}$. Désormais, ce sera surtout par son enseignement à deux générations d'étudiants qu'il diffusera sa vision autonomiste du passé, du présent et de l'avenir de l'Acadie.

\section{B. Gaétan Gervais ou l'ancrage historique des Franco- Ontariens}

Le deuxième historien que nous suivons jusqu'à l'orée du $\mathrm{XXI}^{\mathrm{e}}$ siècle est Gaétan Gervais. Né en 1944 à Sudbury, c'est un fils de mineur qui passe sa prime enfance dans le quartier francophone et largement ouvrier du Moulin-à-Fleur. Élève studieux, il commence en 1958 des études classiques au Collège du Sacré-Cœur, où il se forme à la culture humaniste des jésuites. Un nouveau monde s'offre à lui :

Ma vie bascule [...]. Tout à coup, j'entends parler latin, je découvre la grande littérature [...]. J'avais tout à coup le sentiment de participer à un monde complexe et enrichissant au sein d'un groupe relativement restreint de Canadiensfrançais convaincus. Cette expérience représente une importante distanciation sociale par rapport à mon milieu d'origine [...]. Je vivais tout à coup dans des milieux distincts. Mais quelle formidable aventure s'enclenchait. ${ }^{35}$

Boulimique de lecture, le jeune Gervais, qui est d'abord intéressé par la géologie et l'architecture, se plonge dans les livres de religion, de philosophe catholique, de littérature française et d'histoire, en plus de s'impliquer dans le groupe des archives du collège, dont il devient président. Sous l'influence du père Guy Courteau, il s'initie à la pensée nationaliste de droite en dévorant les pages de la revue Laurentie, organe de l'Alliance

34. Léon Thériault, «L'Acadie du Nouveau-Brunswick et le Québec », op.cit., p. 49-71 ; Id., « L'Évolution des relations extérieures de l'Acadie (1763-1978) », Égalité, no 12, 1984, p. 19-47 ; Id., "Les Origines de l'archevêché de Moncton, 1835-1936 », Les Cahiers de la Société historique acadienne, vol. 17, n 4, 1986, p. 111-132 ; Id., « Parallèles Acadie-Québec. De 1864 à nos jours », Égalité, n 33, 1993, p. 103-124.

35. Cité dans Robert Arseneault, Gaétan Gervais. Le " gardien du dépôt », Ottawa, Centre de ressources pédagogiques de l'Ontario, « Des gens d'exception », 2012, p. 15. 
laurentienne, et il est aussi l'assistant de recherche du folkloriste Germain Lemieux ${ }^{36}$.

En 1962, c'est fort de ces expériences que Gervais commence son baccalauréat en histoire à la nouvelle Université Laurentienne, où il joue un rôle actif dans le journal étudiant, en y devenant le rédacteur français. Il développe alors des affinités avec les thèses sur la décolonisation et avec l'indépendantisme québécois, tout en étant très critique face à la mouvance de la contre-culture et de la contestation sociale qui commence alors à Sudbury. C'est à la Laurentienne que Gervais devient militant en s'engageant au sein de l'Association des étudiants de langue française du Nord de l'Ontario (AdELFNo). À titre de membre du conseil de cette organisation, il est ainsi le principal auteur d'un mémoire qu'il présente devant la Commission Laurendeau-Dunton en $1964^{37}$. Beaucoup plus tard, il dira que c'est son engagement à l'ADELFNo qui lui fera « comprendre la valeur des actions ciblées sur le terrain ${ }^{38}$ »

Après avoir enseigné l'histoire en $11^{\mathrm{e}}$ et $12^{\mathrm{e}}$ années au Collège du Sacré-Cœur en 1965-1966, Gervais s'inscrit à la maîtrise à l'Université d'Ottawa. Sous la direction de Marcel Hamelin, il rédige une thèse sur le journaliste libéral et annexionniste Médéric Lanctot, dont il tirera sa première note de recherche ${ }^{39}$. Puis, pour le doctorat, il se réoriente vers l'histoire économique en travaillant sur 1'expansion du réseau de chemins de fer au Québec, toujours sous la direction d'Hamelin ${ }^{40}$.

En 1972, Gervais revient à la Laurentienne comme chargé de cours. Occupé par la rédaction de sa thèse de doctorat, il mène

36. François-Olivier Dorais, Un historien dans la Cité, op. cit., p. 22-29; FrançoisXavier Chamberland, L'Ontario se raconte de A à X, Toronto, Éditions du Gref, 1998, p. 299.

37. François-Olivier Dorais, Un historien dans la Cité, op. cit., p. 31-47.

38. Cité dans Robert Arseneault, op. cit., p. 23.

39. Gaétan Gervais, « Médéric Lanctot et l'Union nationale », thèse de maîtrise (histoire), Université d'Ottawa, 1968, 189 p. ; Id., «Un souverainiste du XIX siècle. Médéric Lanctot, 1838-1877 », dans Fernand Dumont, Jean Hamelin et Jean-Paul Montminy (dir.), Idéologies au Canada français 1850-1900, Québec, Presses de l’Université Laval, 1971, p. 265-274.

40. Gaétan Gervais, «L'Expansion du réseau ferroviaire québécois (1875$1895)$ », thèse de doctorat (histoire), Université d'Ottawa, 1979, 538 p. 
parallèlement des activités d'animateur communautaire dont les outils de choix sont l'enseignement et la recherche ${ }^{41}$. En plus de ses nombreuses interventions publiques et d'un engagement de tous les instants dans la vie universitaire, Gervais contribue à l'élaboration de divers outils à caractère documentaire, souvent dans une perspective régionale et locale : des bibliographies, des travaux sur l'histoire du Nord-Est ontarien et de la ville de Sudbury, un projet d'histoire orale, un dictionnaire biographique, un ouvrage toponymique, un guide de rédaction en histoire locale, un tour d'horizon de quelques dépôts d'archives. Il continuera de s'investir dans ce type de travail jusqu'à la fin de sa carrière ${ }^{42}$.

En 1979, ayant obtenu son doctorat, Gervais devient professeur en titre. C'est à ce moment qu'il commence à se consacrer à l'histoire des Franco-Ontariens. Au fil des ans, il fera paraître une série d'articles et de chapitres de livres sur la genèse des questions discutées en Ontario français dans les deux dernières décennies du $\mathrm{Xx}^{\mathrm{e}}$ siècle $^{43}$. Tour à tour, il étudie les stratégies de l'élite traditionnelle ${ }^{44}$, la question universitaire ${ }^{45}$, les institutions ${ }^{46}$,

41. Robert Arseneault, op. cit., p. 32.

42. Il serait fastidieux d'énumérer tous les titres. Pour une liste exhaustive, nous renvoyons le lecteur à François-Olivier Dorais, Un historien dans la Cité, op. cit., p. 232-237.

43. Ce n'est qu'au tournant des années 2000 que Gervais publie des ouvrages sur l'Ontario français : Les Jumelles Dionne et l'Ontario français (1934-1944), Sudbury, Prise de Parole, 2000, 246 p. ; Des Gens de résolution. Le passage du « Canada français » à " l'Ontario français », Sudbury, Prise de Parole, 2003, 230 p. ; avec Michel Bock, L'Ontario français des Pays-d'en-Haut à nos jours, Ottawa, Centre de ressources pédagogiques de l'Ontario, 2004, $271 \mathrm{p}$.

44. Gaétan Gervais, «La Stratégie de développement institutionnel de l'élite canadienne-française de Sudbury ou le triomphe de la continuité », Revue du NouvelOntario, $\mathrm{n}^{\circ} 5,1983$, p. 67-92.

45. Id., « L’Enseignement supérieur en Ontario français (1848-1965) », Revue $d u$ Nouvel-Ontario, $\mathrm{n}^{\circ}$ 7, 1985, p. 11-52 ; Id., « L'Ontario français et les universités bilingues (1960-1992) », Éducation et francophonie, vol. 20, nº 3, décembre 1992, p. 31-42.

46. Id., « Le Problème des institutions en Ontario français », Revue du NouvelOntario, no 8, 1986, p. 9-12. 
le bilinguisme ${ }^{47}$, l'enseignement de l'histoire $^{48}$, le Règlement $17^{49}$, l'historiographie ${ }^{50}, 1^{\prime}$ identité $^{51}$, les grands congrès patriotiques ${ }^{52}$, les États généraux du Canada français ${ }^{53}$, les droits linguistiques ${ }^{54}$. Pour lui, la filiation entre le passé, c'est-à-dire l'âge français et canadien-français, et le présent, soit l'âge franco-ontarien, est linéaire. En d'autres mots, “"l'identité franco-ontarienne”, comme "l'identité québécoise", et malgré des ruptures profondes, ne sera jamais que le prolongement de 1' "identité canadienne-française", elle-même le prolongement de 1' "identité française" 55 ". De toute façon, argumente Gervais, la transformation identitaire de l'Ontario français est artificielle, car elle est essentiellement le fruit d'un facteur exogène, le retrait du Québec du Canada français, retrait qui prend, à ses yeux, figure de trahison. C'est un « coup d'État culturel ${ }^{56} »$ aux conséquences dramatiques pour les Franco-

47. Id., « L'Évolution du bilinguisme en Ontario », Langue et société, été 1989, p. $39-41$.

48. Id., « L'Enseignement de l'histoire en Ontario français », Éducation et francophonie, vol. 19, n 2 , août 1991, p. 8-11.

49. Id., « Le Règlement 17 (1912-1927) », Revue du Nouvel-Ontario, $\mathrm{n}^{\circ}$ 18, 1996, p. 123-192.

50. Id., « L'Historiographie franco-ontarienne. À l'image de l'Ontario français », dans Jacques Cotnam, Yves Frenette et Agnes Whitfield (dir.), La Francophonie ontarienne. Bilan et perspectives de recherche, Ottawa, Le Nordir, 1995, p. 123134.

51. Id., "Aux Origines de l'identité franco-ontarienne », Cahiers Charlevoix. Études franco-ontariennes, vol. 1, Sudbury, Prise de Parole et Société Charlevoix, 1995, p. 124-168.

52. Id., " L'Ontario français et les grands congrès patriotiques canadiensfrançais (1883-1952) », Cahiers Charlevoix, vol. 2, Sudbury, Prise de Parole et Société Charlevoix, 1997, p. 9-155.

53. Id., « L'Ontario français et les "États généraux du Canada français" (19661969) », Cahiers Charlevoix. Études franco-ontariennes, vol. 3, Sudbury, Prise de Parole et Société Charlevoix, 1998, p. 231-364 ; Id., " La Présence de l'Ontario aux États généraux du Canada français », dans Marcel Martel, Les États généraux $d u$ Canada français, op. cit., p. 117-132.

54. Id., « Les Droits du français en Ontario. L'argumentation traditionnelle des élites à l'époque du Canada français », dans Marc Cousineau (dir.), La Communauté franco-ontarienne. Un peuple, ses droits et son destin. Actes du colloque tenu à Ottawa le 11 août 2000, Sudbury, Institut franco-ontarien, 2001, p. 47-65.

55. Id., « Aux origines de l'identité franco-ontarienne », op.cit., p. 168.

56. Id., « L'Historiographie franco-ontarienne », op.cit., p. 124. 
Ontariens qui « [...] ont eu un grand sentiment de dépossession, parce qu'on leur arrachait en somme ce qui leur appartenait ${ }^{57}$ ».

Comme le remarque Michel Bock, l'identité franco-ontarienne telle que la conçoit Gervais se fonde à la fois sur le partage d'une mémoire collective et sur la volonté de se perpétuer en s'institutionnalisant, à l'image de la stratégie de l'élite traditionnelle ${ }^{58}$. Tout au long de son parcours, Gervais pose donc une série de gestes pour incruster dans les esprits cette autonomie souhaitée de la minorité franco-ontarienne, d'abord la création d'un drapeau en $1975^{59}$, puis la promotion des petites et moyennes entreprises ainsi que du secteur de la coopération, garant d'un plus grand contrôle de la production et de la consommation. Comme le remarque François-Olivier Dorais, Gervais est alors au diapason avec les priorités de l'AcFo de Sudbury et de l'AcFo provinciale, tout en s'inscrivant dans la tradition du nationalisme économique canadien-français ${ }^{60}$. En collaboration avec Jean-Pierre Pichette, un professeur québécois d'ethnologie installé à Sudbury au début des années quatre-vingt, Gervais s'engage dans plusieurs institutions, tels le Centre franco-ontarien de folklore ${ }^{61}$, la Société historique du Nouvel-Ontario, l'Institut franco-ontarien (dont il a été l'un des fondateurs en 1976), la Revue du Nouvel-Ontario, qui date de 1978, et la Revue de l'Université Laurentienne. Au début de la décennie de 1990, les deux universitaires mettent sur

57. Cité dans François-Xavier Chamberland, op. cit., p. 304.

58. Michel Bock, « Des braises sous les cendres. L'Ontario français et le projet national canadien-français au lendemain des États généraux (1969-1991) », dans Laniel et Thériault, op. cit., p. 187.

59. Robert Arseneault, op. cit., p. 78. Pour des études sur le drapeau francoontarien, voir Guy Gaudreau (dir.), Le Drapeau franco-ontarien, Sudbury, Prise de Parole, 2005, 140 p.

60. François-Olivier Dorais, « Gaétan Gervais. Un intellectuel franco-ontarien entre ruptures et constantes », op.cit., p. 119.

61. Entre 1991 et 1994, les deux amis dirigent un grand projet d'inventaire du patrimoine franco-ontarien : Jean-Pierre Pichette et Gaétan Gervais, "Avant-propos », dans Habiter le pays. Inventaire du patrimoine de l'Ontario français, Sudbury, Prise de Parole et Centre franco-ontarien de folklore, 2001, p. 8-9. Voir aussi Serge SaintPierre (dir.), Répertoire du patrimoine franco-ontarien. Le nord de l'Ontario et les comtés unis de Prescott et de Russell, Sudbury, Centre franco-ontarien de folklore, 1993, $335 \mathrm{p}$. 
pied une amicale vouée à l'étude de l'Ontario français, la Société Charlevoix, et ils œuvrent au grand projet de Dictionnaire des écrits de l'Ontario français qui verra le jour quelque vingt ans plus tard ${ }^{62}$. Pendant presque quarante ans, l'influence de Gervais est tout aussi, sinon plus, manifeste en salle de classe, où il forme des centaines d'étudiants à l'histoire des Franco-Ontariens, dont il inaugure l'enseignement à la Laurentienne en 1978-197963. Certains d'entre eux contribueront à leur tour au progrès des connaissances en rédigeant des mémoires de maîtrise sur divers aspects de l'Ontario français ; plus nombreux seront ses disciples qui œuvreront dans les écoles secondaires, les conseils scolaires, les ministères du gouvernement de l'Ontario. Lui-même donnera de nombreuses conférences à des auditoires variés, interviendra souvent dans les médias écrits et électroniques, sera hautfonctionnaire au ministère de l'Éducation (1987-1989) et présidera le Conseil de l'éducation et de la formation franco-ontarienne (1991-1994). Gervais sera l'un des premiers à se faire l'apôtre de la création d'une université de langue française en Ontario. C'est dans la même logique que, dans les années soixante-dix, il s'est engagé pour mettre sur pied des structures autonomes de langue française, comme membre du Comité des affaires francophones de la Laurentienne, et, à la décennie suivante, pour développer des programmes d'études spécifiquement adaptés aux étudiants franco-ontariens, dans le cadre de ses fonctions à titre de directeur du Conseil de 1'enseignement en français (1981-1987) ${ }^{64}$. C'est d'ailleurs dans la question universitaire « qu'il a investi ses plus vives énergies et tenté d'y traduire ses plus profondes aspirations pour l'Ontario français ${ }^{65} »$.

62. Gaétan Gervais et Jean-Pierre Pichette (dir.), Dictionnaire des écrits de l'Ontario français, 1613-1993, Ottawa, Presses de l'Université d'Ottawa, 2010, XXXVI$1097 \mathrm{p}$.

63. François-Olivier Dorais, Un historien dans la Cité, op. cit., p. 95.

64. Ibid., p. 82-85.

65. Ibid., p. 185. Voir aussi Michel Bock et François-Olivier Dorais, « Quelle université pour quelle société ? Le débat intellectuel sur la question universitaire en Ontario français », Revue du Nouvel-Ontario, n 41, 2016, p. 158-162. 
Gaétan Gervais a fait « œuvre d'historien et de militant, le premier se nourrissant du second et vice versa ${ }^{66} »$. C'est un mariage qui n'est pas toujours heureux. Issu d'une tradition empiriste en histoire, dans le sillage de ses maîtres Marcel Hamelin et Marcel Trudel, Gervais se situe au tout début de sa carrière à l'aune de l'histoire politique, de l'histoire des idéologies et de l'histoire économique. Sa conception empiriste du métier d'historien demeurera dans ses travaux les plus substantiels. Cependant, dans ses textes plus courts, Gervais tend souvent vers un lyrisme qui n'exclut pas les formules lapidaires. En fait, peut-être de façon inconsciente, s'érige-t-il en « historien national » des Franco-Ontariens, tout comme Groulx était l'historien national du Canada français à une autre époque. Gervais a fréquenté l'œuvre du prêtre-historien, qui l'a influencé dans sa conception de l'association histoire-mémoire et de la communauté en tant que corps organique. Il a probablement lu Michel Brunet aussi, sa pratique de l'histoire semblant se situer autant, sinon plus, dans la mouvance de l'École de Montréal que dans celle de Québec, en dépit de son passage au Département d'histoire de l'Université d'Ottawa, alors dominé par l'approche lavalloise et son émulation de l'École des Annales ${ }^{67}$.

Chez Gervais, il n'y a pas de place pour la fragmentation ou les divisions de classes, de genres et de générations. Il n'y a pas de place non plus pour les relations avec les différents groupes ethnoculturels qui ont formé 1'Ontario ${ }^{68}$. De fait, l'historien de Sudbury se positionne, sans toutefois se commettre, contre toute une série de travaux réalisés au tournant des années quatre-vingt et regroupés autour du paradigme de l'ethnicité69 ${ }^{6}$. Il est aussi en

66. Michel Bock, «Préface », dans François-Olivier Dorais, Un historien dans la Cité, op. cit., p. xiii.

67. Sur l'historiographie québécoise au $\mathrm{xx}^{\mathrm{e}}$ siècle, voir Serge Gagnon, Quebec and its Historians. The Twentieth Century, Ottawa, University of Ottawa Press, 1998, 224 p. ; Ronald Rudin, Faire de l'histoire au Québec, Québec, Septentrion, 1998, 278 p. Contrairement à François-Olivier Dorais, nous ne voyons aucune trace de l'École des Annales dans l'œuvre de Gervais, Un historien dans la Cité, op. cit., p. 118-119.

68. François-Olivier Dorais, « Gaétan Gervais. Un intellectuel franco-ontarien entre ruptures et constantes ", op.cit., p. 124-125.

69. Comme l'a montré Marie LeBel, op. cit., Gervais, dans ses écrits, établit 
réaction au mouvement contre-culturel qui anime alors plusieurs intellectuels et artistes du Nouvel-Ontario, et dont le discours lie la « franco-ontarianité » à la marginalité, à l'hybridité et au bilinguisme $^{70}$. En outre, selon lui, ces intellectuels et ces artistes sont distraits par les « bébelles » que sont le théâtre et la chanson plutôt que de s'occuper de donner à la collectivité franco-ontarienne de solides assises économiques ${ }^{71}$. Enfin, à ceux qui, tel le sociologue Donald Dennie ${ }^{72}$, défendent l'idée que le Canada français n'est que le produit d'une fabulation de l'esprit d'un corps d'élite dominant, il rétorque que les Franco-Ontariens ont la conscience de former une société distincte, car leur identité procède d'une double fondation, celle d'une expérience historique et celle d'une expérience culturelle commune ${ }^{73}$.

L'œuvre militante et historienne de Gervais s'inscrit dans l'institutionnalisation et l'autonomisation du savoir sur l'Ontario français qui lui-même participe du phénomène de provincialisation de l'identité franco-ontarienne. Nous en voulons pour preuve la fondation en 1972 de l'Institut d'études pédagogiques de 1'Ontario, à Toronto, dont la section franco-ontarienne deviendra plus tard le Centre de recherche en éducation francoontarienne ; la mise sur pied à Sudbury en 1976 de l'Institut francoontarien, qui lancera, deux années plus tard, la Revue du NouvelOntario ; l'expansion du Centre de recherche en civilisation canadienne-française (CRCCF) et son adoption d'une vocation francoontarienne $^{74}$. Les universitaires de l'Ontario français scrutent alors

rarement de relation directe avec ses pairs.

70. Sur cette question, voir Lucie Hotte, « Littérature et conscience identitaire. L'héritage de CANO », dans Andrée Fortin (dir.), Produire la culture, produire l'identité ?, Québec, Presses de l’Université Laval, 2000, p. 53-68.

71. François-Olivier Dorais, Un historien dans la Cité, op. cit., p. 68-71.

72. Donald Dennie, «De la difficulté d'être idéologue franco-ontarien », Revue du Nouvel-Ontario, $\mathrm{n}^{\circ} 1,1978$, p. 69-90.

73. Gaétan Gervais, « La Stratégie de développement institutionnel de l'élite canadienne-française de Sudbury ou le triomphe de la continuité », op. cit., p. 69.

74. Sur le CrCcF, voir Yves Frenette (dir.), Le Centre de recherche en civilisation canadienne-française 1958-2008. Archives, recherche, diffusion, Ottawa, Le Nordir et CRCCF, 2008, 130 p. 
la vie franco-ontarienne et en débattent ${ }^{75}$. En parallèle, on assiste à Sudbury à un renouveau culturel et artistique axé principalement sur la spécificité franco-ontarienne et sur le caractère ouvrier de la population du Moyen-Nord. À travers leurs productions respectives, écrivains, artistes, dramaturges, chansonniers, cinéastes captent les nouvelles réalités francophones et les traduisent sous des formes propices à leur rayonnement. La coopérative artistique CANO voit le jour et donne naissance au groupe musical du même nom. Apparaissent aussi une maison d'édition, Prise de Parole, et le festival La Nuit sur l'Étang ${ }^{76}$. En revanche, si ce mouvement contre-culturel participe du même processus qui engendre un Gaétan Gervais, ils sont à des années-lumière l'un de l'autre ${ }^{77}$.

\section{Robert Painchaud : l'ambiguiité identitaire des Franco- Manitobains}

L'Ouest francophone de la fin du $\mathrm{Xx}^{\mathrm{e}}$ siècle ne produit pas de Léon Thériault ou de Gaétan Gervais, peut-être parce que l'avènement de quatre identités provinciales distinctes ne permet à aucun historien de s'imposer. Le chercheur dont le rôle se rapproche le plus de celui de Thériault et de Gervais est le Franco-Manitobain Robert Painchaud. Malheureusement, un accident d'avion le fait disparaître tragiquement en 1978, avant qu'il ne puisse donner sa pleine mesure.

Comme en Acadie et en Ontario français, la Prairie connaît des transformations importantes à partir de la Deuxième Guerre

75. Serge Dupuis et Stéphane Savard, « Arpenté, défriché, mais pas encore entièrement labouré. Le champ de l'historiographie franco-ontarienne en bref », Bulletin d'histoire politique, vol. 24, $\mathrm{n}^{\circ} 2$, hiver 2016, p. 11.

76. Sur ces années d'effervescence, voir Fernan Carrière, « La Métamorphose de la communauté franco-ontarienne, 1960-1985 », dans Cornelius Jaenen (dir.), Les Franco-Ontariens, Ottawa, Presses de l'Université d'Ottawa, 1993, p. 305-339; Gaston Tremblay, Prendre la parole. Le journal de bord du Grand CANO, Hearst, Le Nordir, 1995, 330 p. ; Marie-Hélène Pichette, Musique populaire et identité francoontarienne. La Nuit sur l'Étang, Sudbury, Prise de Parole, 2001, 124 p. ; Gratien Allaire et Michel Giroux (dir.), Fernand Dorais et le Nouvel-Ontario. Réflexions sur l'œuvre et sur l'influence d'un provocateur franco-ontarien, Sudbury, Institut francoontarien, 2007, 181 p.

77. Marie LeBel, op. cit. 
mondiale et surtout à partir du début des années soixante. En effet, la prospérité du secteur agricole et la mécanisation des fermes ont des effets tout à la fois heureux et désastreux pour les francophones de l'Ouest. La hausse de la production de blé permet aux fermiers de subvenir à leurs besoins et la mécanisation facilite leur vie. Cependant, le prix croissant de la machinerie en met plusieurs dans l'embarras. Ils doivent accroître la superficie de leur exploitation ou quitter la terre. Au fil des ans, plusieurs choisissent de vendre leur ferme à un voisin et de chercher un emploi en ville, un déménagement porteur de lourdes conséquences linguistiques. Entouré dans sa paroisse rurale de voisins qui parlent la même langue que lui, chef de sa propre entreprise, le francophone de l'Ouest peut gagner sa vie en français, pratiquer sa religion en français et s'amuser en français. Sauf dans le petit centre institutionnel de Saint-Boniface, c'est rarement le cas en ville ${ }^{78}$.

En parallèle, les gouvernements provinciaux élaborent des politiques de modernisation et de centralisation propres aux Trente Glorieuses. Au Manitoba, le gouvernement conservateur de Duff Roblin, au pouvoir de 1958 à 1967, crée, d'un côté, de grandes unités scolaires qui minent les communautés rurales de langue française et, de l'autre, rétablit progressivement l'enseignement du français qui se faisait dans l'illégalité depuis 1916. C'est dans ce contexte qu'a lieu au sein de la francophonie manitobaine un conflit de générations qui mène à la déconfessionnalisation et au remplacement de l'élite traditionnelle par une élite modernisatrice et plus militante, un changement de garde symbolisé par la transformation de l'Association d'éducation canadienne-française du Manitoba en Société franco-manitobaine ${ }^{79}$.

78. Robert Painchaud, «The Franco-Canadian Communities of Western Canada since 1945 », Western Canadian-Atlantic Studies Conference, Calgary, février 1978 et Frédéricton, avril 1978, 25 p. Fonds Robert-Painchaud (PO27) (dorénavant FRP), aux Archives et collections spéciales de la Bibliothèque Alfred-Monnin, à l'Université de Saint-Boniface, Préarchivage ; André Lalonde, «Les Canadiens français de l'Ouest. Espoirs, tragédies, incertitude », dans Dean Louder et Eric Waddell (dir.), op. cit., p. 81-95.

79. Sur ces questions, voir Raymond Hébert, La Révolution tranquille au Manitoba français, Saint-Boniface, Éditions du Blé, 2012, 386 p. ; Jacqueline Blay, Histoire du Manitoba français, T. 3, De Gabrielle Roy à Daniel Lavoie (1916-1968), 
Né en 1941 à Saint-Boniface, Robert Painchaud est impliqué dès son jeune âge dans la vie française de la localité. Il est scout et, en 1951, alors qu'il n'est âgé que de neuf ans, le petit garçon est choisi pour présenter un bouquet de fleurs à la princesse Elizabeth quand elle passe par Saint-Boniface. Pour ses études secondaires et supérieures, il fréquente le Collège de Saint-Boniface, où il se mérite plusieurs prix et où il s'initie au théâtre. Il y obtient un baccalauréat ès arts en 1961 et un certificat en éducation en 1963. Puis, pendant trois ans, il enseigne à l'École secondaire de Lorette, localité située à une trentaine de kilomètres au sud-est de Saint-Boniface. Après avoir obtenu son baccalauréat en éducation à son alma mater en 1965, il y demeure comme enseignant au palier secondaire. Décidant de poursuivre ses études en histoire à l'Université de Winnipeg, il en ressort avec un baccalauréat spécialisé en 1968. Boursier Woodrow Wilson, il part faire sa maîtrise à l'Université d'Ottawa, sous la supervision de Cornelius Jaenen qui, comme lui, est natif de l'Ouest. Après avoir soutenu sa thèse en 1969, Painchaud entreprend des études doctorales, toujours sous la direction de Jaenen. L'année suivante, il accepte un poste à l'Université de Winnipeg, où il donne des cours sur l'histoire sociale et intellectuelle du Canada, la politique étrangère canadienne, les relations entre francophones et anglophones, ainsi que sur l'Ouest. Après avoir obtenu un congé d'enseignement de deux ans, il soutient sa thèse de doctorat en $1976^{80}$.

Painchaud est très attaché à Saint-Boniface. Après son mariage en 1974, il choisit d'y habiter et est très engagé dans la communauté. Président de la chorale des Intrépides, le jeune professeur est aussi actif à la Société historique de Saint-Boniface, dont il édite huit numéros de son bulletin, en plus d'agir comme viceprésident. En 1974, avec Annette St-Pierre, il est cofondateur des Éditions du Blé, dont il assume la direction deux ans plus tard. Le duo réitère en mettant sur pied le Centre d'études francocanadiennes de 1'Ouest (CÉFCO) en 1978. Modelée sur le CRCCF

Saint-Boniface, Éditions des Plaines, 2016, 465 p.

80. Nous avons établi ce profil à partir de divers documents contenus dans FRP). 
et sur le Centre d'études acadiennes de l'Université de Moncton, la nouvelle entité a pour objectif d'inventorier et de valoriser l'apport des francophones de l'Ouest à la société canadienne. Les deux animateurs obtiennent une subvention de 100000 \$ du Secrétariat d'État ${ }^{81}$.

Dans sa thèse de maîtrise, Painchaud se penche sur l'immigration canadienne-française au Manitoba dans les vingt premières années du régime confédératif ${ }^{82}$. Après avoir décrit le rôle du gouvernement fédéral, il s'attarde aux efforts de l'élite laïque et cléricale pour attirer des migrants du Québec et des États-Unis, puis il traite des conditions matérielles des colons et il en trace un portrait, avant d'analyser la population de langue française de la province, à partir du recensement canadien de 1891. Dans l'introduction, il déclare vouloir « redresser » l'interprétation nationaliste à l'effet que le peuplement de l'Ouest s'est effectué au détriment des Canadiens français. Si cette assertion semble quelque peu naïve ${ }^{83}$, les questions posées par l'auteur témoignent de beaucoup d'originalité en regard de l'historiographie de l'époque. Ainsi veut-il distinguer les caractéristiques des colons provenant directement du Québec de celles des migrants québécois étant passés par les États-Unis. Quant à son chapitre sur la structure de la population, il est très novateur. Mais, de son propre aveu, la recherche de Painchaud est incomplète.

Pour sa thèse de doctorat, qui sera traduite en français et publiée de façon posthume, Painchaud approfondit certains aspects de sa thèse de maîtrise, mais surtout il élargit son enquête

81. La Liberté, 29 juin 1978.

82. Robert Painchaud, « Le Manitoba et l'immigration canadienne-française, 1870-91 », thèse de maîtrise (histoire), Université d'Ottawa, 1969, 416 p. Demeurée inédite, la thèse fera néanmoins l'objet d'une conférence à la Société historique de Saint-Boniface en 1971 : «Vue d'ensemble sur la colonisation au Manitoba français et catholique après 1870 », Conférence présentée à la Société historique de SaintBoniface, 25 janvier 1971, 29 p., FRP, PO27-010-003.

83. Presque une décennie plus tard, Painchaud entend reprendre sa critique dans des communications aux congrès annuels de la Société historique du Canada et de l'Institut d'histoire de l'Amérique française, respectivement en juin et en octobre 1978 : Painchaud, «The Franco-Canadian Communities of Western Canada since 1945 », op. cit. 
jusqu'à la Première Guerre mondiale et il traite de la Prairie dans son ensemble. Il porte son attention sur le discours et sur l'action de la hiérarchie épiscopale et de l'élite laïque de l'Ouest, avec la collaboration du gouvernement fédéral, pour peupler la région avec des francophones, dans le but d'y préserver et d'y renforcer les acquis des franco-catholiques. Dès la création du Manitoba, l'archevêque de Saint-Boniface, $\mathrm{M}^{\mathrm{gr}}$ AlexandreAntonin Taché, met en place un plan pour que les Canadiens français et les Métis continuent d'occuper et, si possible, de dominer démographiquement le territoire. Son successeur, $\mathrm{M}^{\mathrm{gr}}$ Adélard Langevin, ainsi que les évêques de Saint-Albert en Alberta et de Prince-Albert en Saskatchewan le modifient au gré des circonstances, mais toujours avec le même objectif en tête. Pour réaliser le projet, il faut d'abord faire en sorte que les Métis demeurent sur les terres qui leur reviennent de droit, puis attirer dans la Prairie des Canadiens français du Québec et des États-Unis. Se rendant compte rapidement que, dans la foulée du peuplement anglophone et allophone, beaucoup de Métis quittent la région et que les Canadiens français ne viennent pas en assez grand nombre, la hiérarchie épiscopale se tourne vers l'Europe francophone comme bassin de recrutement. Si cette stratégie amène des milliers de franco-catholiques dans la Prairie, elle est loin de connaître le succès, l'Ouest se peuplant plutôt avec des immigrants des Îles britanniques ainsi que de l'Europe centrale et orientale. En 1911, la population non amérindienne de la Prairie se chiffre ainsi à 1,7 millions, dont seulement 90000 personnes sont d'origine ethnique française $(6 \%)$. En fait, les autorités ecclésiastiques contribuent elles-mêmes à marginaliser les francophones, car, en parallèle, elles encouragent la venue de catholiques allophones ${ }^{84}$.

84. Robert Painchaud, «The Catholic Church and the movement of Francophones to the Canadian Prairies, 1870-1915 », thèse de doctorat (histoire), Université d'Ottawa, 1976, 468 p. ; Id., Un rêve français dans le peuplement de la Prairie, Saint-Boniface, Éditions des Plaines, 1987, 303 p. Dans la foulée de ses recherches doctorales, Painchaud fait paraître Le Peuplement francophone dans les prairies de l'Ouest 1870-1920, Ottawa, Musée national de l'Homme et Office national du film du Canada, « Histoire du Canada en images », série 1, vol. 19, 1974, 20 p. Voir aussi Id., « Les Origines des peuplements de langue française dans l'Ouest canadien, 18701920. Mythes et réalités », Délibérations et mémoires de la Société royale du Canada, 
Ainsi, la question de l'immigration francophone apparaît très tôt dans l'ADn de l'élite militante de la Prairie, où les journaux de langue française l'associent aux luttes politico-religieuses et à la survie culturelle ${ }^{85}$. En y consacrant ses thèses de maîtrise et de doctorat, Painchaud témoigne de son ancrage dans la société franco-manitobaine, à un moment où lui-même et l'élite prennent conscience des effets dévastateurs de l'assimilation linguistique. $\mathrm{Au}$ début de 1975, le jeune historien donne une entrevue au journal Winnipeg Tribune dans laquelle il parle du sentiment d'aliénation qui s'est emparé de ses compatriotes en raison de cette situation et aussi de leur abandon par le Québec. Dans le même article, il prêche la tolérance et l'accommodement : «As Franco-Manitobans command and demand respect for their linguistic and cultural survival, so too must they attempt to respect the linguistic and cultural ambitions of Western Canada's other cultural minorities $^{86}$. " À une autre occasion, il déclare que le Canada a toujours été un pays pluraliste et que « we all enjoy $a$ special status ${ }^{87} »$.

Painchaud paraît être un messager de la bonne entente entre les différents éléments ethnoculturels de la Prairie. Il est sans doute significatif qu'il rédige sa thèse de doctorat en anglais et qu'il compte la publier aux Presses de 1'Université McGill ${ }^{88}$. En mars 1974, dans le cadre du centenaire de Winnipeg, la Société historique de Saint-Boniface, où, comme on l'a vu, il joue un rôle de premier plan, organise une exposition sur la contribution des hommes d'affaires et des entreprises francophones au développement de la ville. L'événement a lieu à l'hôtel Empress,

Quatrième série, T. XIII, 1975, p. 109-121 ; Id., « Les Exigences linguistiques dans le recrutement d'un clergé pour l'Ouest canadien, 1818-1920 », Sessions d'étude de la Société canadienne d'histoire de l'Église catholique, 1975, p. 43-64.

85. Jean-Philippe Croteau, France Martineau et Yves Frenette, « Les Représentations du Canada français et de sa langue dans la presse en 1912-1913 », dans Laurence Arrighi et Karine Gauvin (dir.), Regards croisés sur les français d'ici, Québec, Presses de l'Université Laval, 2017, p. 173-198.

86. Winnipeg Tribune, 20 janvier 1975.

87. Winnipeg Free Press, 2 mars 1974.

88. La Liberté, 29 juin 1976. 
un lieu symbolique, car il s'agit de l'ancien Bloc Cauchon, du nom de l'entrepreneur et lieutenant-gouverneur Joseph-Édouard Cauchon, qui l'a fait ériger en $1883^{89}$. De plus, en 1975 et en 1976 , Painchaud participe aux deux premières conférences nationales sur le multiculturalisme ${ }^{90}$. Il est également membre du Conseil consultatif de l'Association canadienne d'études ethniques et du Comité consultatif sur le multiculturalisme mis sur pied par le gouvernement du Manitoba. Il apparaît sur diverses tribunes, prenant la parole et écrivant sur des sujets d'actualité. Souvent invité à la radio et à la télévision, il explique le Canada français aux anglophones et le Canada anglais aux francophones. Dans la même veine, comme son confrère André Lalonde à l'Université de Régina, il explique les réalités francophones de l'Ouest aux Québécois, et vice-versa ${ }^{91}$. Intéressé par la politique, tant municipale que provinciale et fédérale, ce n'est qu'une question de temps, croit-on, avant qu'il ne se lance dans l'arène ${ }^{92}$.

Mais lui-même le souhaite-t-il ? En tout cas, dans un court tapuscrit non daté et non paginé, il trace un programme de recherche : il voudrait étudier la formation de l'identité « francomanitobaine » et comprendre pourquoi certains francophones ne se reconnaissent pas dans cette appellation ou encore dans l'appellation « canadienne-française » :

Existe-t-il là des nuances qui pourraient révéler des conflits, des querelles passées, mais qui ont laissés $[$ sic $]$ des cicatrices [...] Je voudrais voir par quels moyens et avec quel [sic] réussite les

89. Winnipeg Free Press, 2 mars 1974. Sur Cauchon, voir Andrée Désilets, «Cauchon, Joseph-Édouard», Dictionnaire biographique du Canada, vol. 11 : (18811890), en ligne au http://www.biographi.ca/fr/bio/cauchon_joseph_edouard_11F. html.

90. Robert Painchaud, « Les Francophones de l'Ouest canadien et le multiculturalisme ", dans Rapport de la Deuxième conférence sur le multiculturalisme, Ottawa, Conseil consultatif canadien du multiculturalisme, 1976, p. 35-62.

91. Robert Painchaud, «Le Vote des francophones à l'élection du 30 juin au Manitoba », Le Devoir, 14 juillet 1973 ; Id., « Des Franco-Manitobains tiraillés... », Perception, novembre-décembre 1977, p. 15-17 ; Id., «Vivre en français au Manitoba. Un témoignage ", Québec français, n 29, mars 1978, p. 62-63; Id., "Les Élections au Québec », Bulletin de la Société historique de Saint-Boniface, n², décembre 1976, p. 2.

92. La Liberté, 11 novembre 1976. 
chefs de file Franco-manitobains [sic] ont réussi à créer l'esprit de corps au sein des groupes francophones qui ont donné naissance et ont nourri la collectivité franco-manitobaine.

Il aimerait également se pencher sur les idéologies dans la province et y lier la question scolaire. Et, se demande-t-il, qu'en est-il de l'apport des congrégations religieuses ? Pourquoi, au $\mathrm{XX}^{\mathrm{e}}$ siècle, les frères et les sœurs ont-ils été remplacés par des laïques dans les écoles ? Plus généralement, Painchaud croit qu'il faut examiner l'élite, son discours, ses valeurs, les outils qu'elle se donne, ses pratiques, son influence sur la population. Enfin, il serait important d'évaluer le mal qu'a pu faire l'émigration, particulièrement les départs vers l'Est : «Avons-nous perdu là un nombre important de chefs, au point où il ne resterait plus chez nous que ceux qui ne peuvent se décider à partir et qui végètent là en attendant l'assimilation ${ }^{93}$ ? / Le programme ambitieux de Painchaud se réaliserait ainsi à l'aune de l'histoire politique, religieuse, intellectuelle et sociale. Il se plaint aussi du fait que l'histoire des femmes de langue française au Manitoba est méconnue et que les manuels d'histoire du Canada accordent trop d'attention aux questions constitutionnelles. "Where's the stuff about people? », demande-t-i194.

Le décès prématuré de Painchaud l'empêche de réaliser son programme. À peine a-t-il le temps de préparer des communications, qui demeurent inédites, sur les relations entre Métis et Canadiens français, entre la naissance du Manitoba et l'Affaire Riel, et sur les Franco-Canadiens de l'Ouest depuis la fin de la Deuxième Guerre mondiale ${ }^{95}$. Comparant leur situation d'alors à

93. Robert Painchaud, « Des questions sur le Manitoba français », FRP, P027010-004. À l'occasion, Painchaud s'éloigne des questions historiques et politiques. Par exemple, il contribue à un ouvrage collectif sur l'éducation : Id., "The FrenchCanadian Child in an English-speaking School System », dans William Byrne et Jack Quarter (dir.), Must Schools Fail ? The Growing Debate in Canadian Education, Toronto, McClelland and Stewart, 1972, p. 251-262.

94. Winnipeg Free Press, 2 mars 1974.

95. Robert Painchaud, « Les Rapports entre les Métis et les Canadiens français au Manitoba, 1870-1884 », Colloque sur les Métis, Université Brandon, 5-6 mai 1977, 30 p., FRP, Préarchivage ; Id., « The Franco-Canadian Communities of Western Canada since $1945 »$, op. cit. 
la situation au moment où il écrit, il fait état des bénéfices collectifs de la Loi sur les langues officielles de 1969, notamment du financement des organisations francophones provinciales, de la mise sur pied d'un institut pédagogique au Collège de Saint-Boniface, de la création d'un centre culturel, de stations de radio et d'une station de télévision de langue française. Selon l'historien, c'est un renversement de situation complet. Même s'il reste beaucoup à faire, "these new measures have given francophones the hope that they could soon take for granted what they previously struggled for and, more importantly perhaps, the facility to concentrate on rehabilitating themselves as a stable and vibrant community ${ }^{96} "$. De grands progrès ont aussi été accomplis quant aux droits scolaires, domaine de juridiction provinciale. Lentement mais sûrement, le nombre d'heures d'enseignement en français s'est accru et le Manitoba a même mis sur pied, en 1976, un Bureau de l'éducation en français.

\section{Conclusion}

Hormis le fait qu'ils soient membres de la même génération, quelles sont les ressemblances et les différences entre Léon Thériault, Gaétan Gervais et Robert Painchaud ? Mais d'abord se connaissent-ils ? Gervais et Painchaud étant tous les deux présents au Département d'histoire de l'Université d'Ottawa entre 1968 et 1970, il est difficile de penser qu'ils ne se croisent pas à 1'occasion. Et, à partir du moment où ils diffusent leurs travaux, se lisent-ils mutuellement? Il se pourrait bien que non, pas au début en tout cas, la francophonie canadienne ne constituant pas une référence. Les références, ce sont le Canada anglais, le Québec, la France peut-être et, naturellement, pour chacun d'entre eux, leur territoire de prédilection, l'Acadie, l'Ontario français, la Prairie francophone.

Et qu'en est-il des thématiques qu'ils développent et de leur conception de l'histoire ? Thériault et Gervais se rejoignent dans

96. Id., « The Franco-Canadian Communities of Western Canada since 1945 », op. cit., p. 6. 
leur quête d'autonomie pour les Acadiens et les Franco-Ontariens. C'est là le thème qui les anime le plus, à la fois comme historiens et comme militants : l'autonomie institutionnelle était présente dans le passé, elle doit devenir encore plus importante dans le présent et dans l'avenir. Thériault va plus loin en s'engageant dans un parti politique autonomiste qui revendique la constitution d'une province acadienne, alors que Gervais consacre sa carrière à l'épanouissement institutionnel des siens. Le tempérament des deux hommes explique peut-être cette différence, mais, même si Gervais avait voulu faire de la politique active, il aurait dû s'engager dans un vieux parti, car en raison des caractéristiques géographiques et sociodémographiques de la population de langue française de l'Ontario, dispersée sur un territoire plus grand que l'Acadie des Maritimes et minoritaire dans toutes les régions de la province, l'autonomie et l'autonomisation de la communauté franco-ontarienne ne peuvent prendre la voie électorale ; elles ne peuvent advenir que dans la sphère institutionnelle et culturelle, dans la foulée du projet collectif séculaire de l'élite traditionnelle.

Les deux historiens montrent un grand respect et même de l'admiration envers les ancêtres. Pour eux, il y a filiation entre les chefs des périodes antérieures et les chefs de leur époque. Thériault et Gervais évaluent positivement le rôle des membres de l'élite. Eux-mêmes sont élitistes. Plus traditionaliste que néonationaliste, Gervais observe avec sympathie l'action du clergé de l'Ontario français d'antan. Plus néonationaliste que traditionaliste, Thériault semble avoir une posture plus distante envers l'institution ecclésiale, même si un examen plus approfondi de ses écrits nous amènerait peut-être à nuancer. Autre différence : pour Thériault, les facteurs endogènes prédominent dans le développement de 1'Acadie, dont les origines sont distinctes de celles du Canada français. En outre, dès la fin du XIX ${ }^{\mathrm{e}}$ siècle, les Acadiens ont exprimé leur caractère distinct en se dotant de symboles bien à eux, ce qui n'empêche pas le Québec d'avoir fait une modeste contribution. Pour Gervais, c'est le contraire : dans sa vision, dans ses analyses, les facteurs endogènes sont absents. 
Jusqu'aux années soixante, l'Ontario français faisait partie d'un grand tout, le Canada français. C'est la volonté de rupture des Québécois qui amena de façon catastrophique le besoin de redéfinition identitaire.

Robert Painchaud exprime aussi un certain ressentiment envers la rupture provoquée par les Québécois, mais il ne s'y attarde pas. En fait, sa posture est a contrario de celles de Thériault et de Gervais. Alors que ceux-ci recherchent l'autonomisation, Painchaud prône l'ouverture à l'Autre. Posons encore une fois la question : est-ce par tempérament? Après tout, Painchaud épouse une femme d'origine ukrainienne et il choisit d'enseigner dans une institution de langue anglaise, apparemment parce qu'il veut travailler dans une université et non dans un collège universitaire ${ }^{97}$. Ou est-ce par réalisme, la situation des francophones des provinces de la Prairie ne se comparant favorablement ni à celle des Acadiens du Nouveau-Brunswick ni à celle des Franco-Ontariens, en raison de la faiblesse de leur nombre et de leur pourcentage dans la population provinciale, ainsi que de la répression culturelle et linguistique dont ils ont été victimes ? Ou encore est-ce par opportunisme, Painchaud et d'autres militants de l'Ouest voyant dans l'action du gouvernement fédéral, notamment dans sa politique de bilinguisme à partir de 1969 et dans sa politique de multiculturalisme, deux ans plus tard, un gage de survie et de promotion de l'identité franco-manitobaine ? Se pourrait-il que l'historien adhérât pleinement à l'idéal d'une société multiculturelle ? Si c'est le cas, a-t-il été influencé par son mentor, Cornelius Jaenen, un fils d'immigrants belges qui, très tôt, est associé à l'entreprise du Secrétariat d'État de donner des assises mémorielles aux groupes ethniques du Canada ${ }^{98}$ ?

Pour l'instant, ces questions devront rester sans réponses. Nous espérons néanmoins que notre démarche a permis de montrer l'intérêt qu'il y a à mettre en relation des parcours historiens

97. Selon une conversation que nous avons eue avec sa sœur Claire.

98. Sur l'avènement du multiculturalisme comme sujet d'étude au Canada, voir Dirk Hoerder, From the Study of Canada to Canadian Studies.To Know our Many Selves Changing across Time and Space, s.1., Wifsner-Verlag, 2005, p. 265-304. 
de différentes aires de la francophonie canadienne à une époque donnée. Un historiographe plus téméraire que nous pourrait même croiser les périodes et élargir son enquête à l'ensemble de la francophonie nord-américaine. 